\title{
The Validity and Reliability of The Instrument Assessment of Higher Order Thinking Skill on The Biological Scope Materials
}

\section{Validitas dan Reliabilitas Instrumen Penilaian Kemampuan Berpikir Tingkat Tinggi pada Materi Ruang Lingkup Biologi SMA}

\author{
Ganda Hijrah Selaras ${ }^{1)}$, Yuni Ahda" ${ }^{1)}$ Heffi Alberida ${ }^{1)}$, \\ Des $\mathrm{M}^{1)}$, Tri Putri Wahyuni ${ }^{1)}$ \\ 1)Jurusan Biologi, FMIPA, Universitas Negeri Padang \\ JIn. Prof. Dr. Hamka, Air Tawar, Padang \\ Email: gandahijrahselaras@gmail.com
}

\begin{abstract}
High Order Thinking Skill (HOTS) requires students to connect, analyze, and also transform their knowledges and experiences. To determine students' high-level thinking skills, we can use assessment instruments. A good instrument should be valid and reliable so it is feasible to measure and assess what it wants to be measured and assessed. Therefore it is necessary to know the level of validity and reliability of the higher order thinking assessment instruments. The instrument used in this study in the scope of biology material. This type of research is descriptive research. The subjects of this study were students of grade X MIPA 5 SMA 5 Padang. Based on the results of data analysis, the assessment instrument of high order thinking skill on biological scope material is logically valid, empirical valid and reliable.
\end{abstract}

Keywords: assessment instrument, validity, reliability, high order thinking skill

\section{PENDAHULUAN}

Kemampuan berpikir tingkat tinggi (High Order Thinking Skill-HOTS) menuntut peserta didik untuk menghubungkan, menganalisis, dan juga mentranformasi pengetahuan dan pengalaman yang dimiliki, tidak hanya sekedar hafalan atau menyampaikan kembali hafalan tersebut. Syafredi (2018: 16-17) mengatakan, "Proses kognitif yang melibatkan kemampuan berpikir tingkat tinggi ialah menganalisis, mengevaluasi, dan menciptakan." Kemampuan berpikir tingkat tinggi merupakan berpikir secara kompleks dan menyeluruh tidak hanya sekedar mengetahui dan memahami materi yang ada.Sejalan dengan pendapat Rofiah, Aminah, dan Ekawati (2013: 18), kemampuan ini merupakan proses berpikir bukan menghafal dan menyampaikan kembali informasi. Peserta didik pada masa SMA termasuk dalam kategori remaja dengan usia 15-17 tahun. Hal ini menujukkan bahwa peserta didik telah mampu mengembangkan kemampuan berpikir tingkat tinggi. Mukhlisah (2015: 124-125) menyatakan, pada usia 11 tahun hingga dewasa manusia 
memiliki pemikiran yang abstrak dan memecahkan masalah dengan penggunaan eksperimentasi sistematik.

Suatu instrumen yang baik hendaknya valid dan reliabel sehingga layak untuk mengukur dan menilai apa yang ingin diukur dan dinilai.Yusuf (2017: 61) menyatakan bahwa konsep validitas menunjukkan kepada kesesuaian, kebermaknaan, dan kebergunaan kesimpulan-kesimpulan yang dibuat berdasarkan skor instrumen. semakin tinggi validitas suatu instrumen, berarti semakin baik kesimpulan yang diambil dan semakin baik pula tingkat kebermaknaan maupun kegunaannya. semakin tinggi validitas suatu alat ukur, maka semakin baik alat ukur itu untuk digunakan. Validitas suatu alat ukur tidak dapat dilepaskan dari kelompok yang dikenai alat ukur tersebut. Karena alat ukur/instrumen yang valid untuk kelompok tertentu, belum tentu valid untuk kelompok yang lain.

Validasi instrumen penilaian kemampuan berpikir tingkat tinggi dilakukan dengan validitasi logis dan validitas empiris. Validitas logis adalah untuk menganalisis kesesuaian instrumen penilaian dengan materi, kontruksi, bahasa, dan kemampuan berpikir tingkat tinggi peserta didik. validitas empiris untuk mendapatkan data yang valid secara empiris dengan uji coba soal.

\section{METODE PENELITIAN}

Jenis penelitian ini adalah penelitian deskriptif Tujuan penelitian ini untuk mengetahui validitas dan reliabilitas instrumen penilaian kemampuan berpikir tingkat tinggi pada materi ruang lingkup biologi pada peserta didik kelas X SMA/MA. Subjek penelitian ialah peserta didik kelas X MIPA 5 SMAN 5 Padang. Objek Penelitian ini ialah validitas dan reliabilitas instrumen penilaian kemampuan berpikir tingkat tinggi materi ruang lingkup biologi untuk peserta didik SMA/MA kelas X.

Teknik analisis data pada penelitian ini menggunakan statistik deskriptif. Teknik ini mendeskripsikan hasil uji validitas dan realibilitas soal kemampuan berpikir tingkat tinggi. Analisis ini meliputi hal-hal sebagai berikut ini.

1. Analisis validitas logis

Analisis validitas logis instrumen penilaian kemampuan berpikir tingkat tinggi meliputi materi, konstruksi, bahasa, dan kemampuan berpikir tingkat tinggi. Analisis dilakukan berdasarkan lembar validasi dengan melakukan beberapa langkah sebagai berikut ini.

a. Memberikan skor jawaban dengan skala Likert yang dimodifikasi dari Arikunto (2012: 180) sebagai berikut ini.

$4=$ sangat setuju $(\mathrm{SS})$

$3=$ setuju $(\mathrm{S})$

2 = tidak setuju (TS)

$1=$ sangat tidak setuju (STS) 
b. Menentukan jumlah kelas untuk kriteria penilaian. Jumlah kriteria penilaian yang digunakan mengacu dengan kriteria penilaian menurut Purwanto (2009) sebagai berikut.

Sangat Baik $\quad=4$

Baik $\quad=3$

Tidak Baik $\quad=2$

Sangat Tidak Baik $=1$

c. Menentukan panjang kelas atau interval kriteria penilaian validitas/praktikalitas menggunakan metode frekuensi data kualitatif yang dikemukakan oleh Supranto (2000: 63-64) menggunakan rumus sebagai berikut.

Keterangan :

$$
\mathrm{C}=\frac{\mathrm{X}_{\mathrm{n}}-\mathrm{X}_{1}}{k}
$$

$\mathrm{C}=$ Panjang kelas/interval

$\mathrm{X}_{\mathrm{n}}=$ Skor tertinggi penilaian

$\mathrm{X}_{1}=$ Skor terendah penilaian

$\mathrm{k}=$ Jumlah kelas

d. Nilai validitas instrumen penilaian kemampuan berpikir tingkat tinggi yang dikembangkan ditentukan dengan statistik deskriptif berupa penilaian rerata menggunakan rumus yang dimodifikasi dari Supranto (2000: 86) sebagai berikut.

$$
\mathrm{Va}=\frac{2_{i=0}^{T_{i}} A i}{n}
$$

Keterangan :

$\mathrm{Va}=$ Rata-rata hasil penilaian validitas

$\mathrm{Ai}=$ Rata- rata Penilaian validitas terhadap $i$

$\mathrm{N} \quad=$ Banyaknya kriteria

Kriteria penilaian validitas instrumen adalah sebagai berikut.

$3,35-4,00=$ Sangat Valid

$2,50-3,34=$ Valid

$1,75-2,49=$ Tidak Valid

$1,00-1,74=$ Sangat Tidak Valid

2. Analisis validitas empiris

Data validitas empiris diperoleh setelah soal diujikan kepada peserta didik. Data ini diperoleh dari hasil analisis butir soal lembar jawaban yang telah diisi peserta didik. Analisis butir soal secara kuantitatif dianalisis menggunakan program ANATES versi 4.09. Nilai validitas ditentukan dengan korelasi sebagai berikut ini.

$0,75-1,00=$ sangat tinggi 


$$
\begin{aligned}
& 0,50-0,75=\text { tinggi } \\
& 0,25-0,50=\text { rendah } \\
& 0,00-0,25=\text { sangat rendah }
\end{aligned}
$$

Suatu instrumen penilaian dikatakan sudah memiliki validitas empiris yang tinggi jika telah memiliki indeks valid 0,50 sampai 0,75 (Arikunto, 2013: 89).

3. Analisis reliabilitas instrumen penilaian kemampuan berpikir tingkat tinggi

Reliabilitas untuk soal kemampuan berpikir tingkat tinggi pilihan ganda dapat diketahui dari analisis butir soal dengan ANATES versi 4.0.9. Suatu tes dikatakan reliabel (memiliki reliabilitas yang tinggi) bila $r_{11}$ sama dengan atau lebih besar dari pada 0,70 , sedangkan bila lebih kecil dari 0,70 maka belum memiliki reliabilitas yang tinggi (Sudjiono, 2011: 254-257).

\section{HASIL PENELITIAN DAN PEMBAHASAN}

Analisis validitas logis instrumen penilaian kemampuan berpikir tingkat tinggi meliputi materi, konstruksi, bahasa, dan kemampuan berpikir tingkat tinggi. Validitas logis pada instrumen penilaian kemampuan berpikir tingkat tinggi ini bertujuan untuk membuktikan kevalidan instrumen penilaian yang digunakan. Validitas logis dilakukan oleh tiga orang validator yang merupakan staf pengajar dari Jurusan Biologi FMIPA UNP, Jurusan Pendidikan IPA FMIPA UNP dan Jurusan Bahasa Indonesia FBS UNP, dengan menggunakan angket validasi. Angket validasi digunakan untuk pengumpulan data dalam lembar validasi (Prasetiyo dan Pertiwi, 2017:23). Selama proses validasi, terdapat beberapa saran dari validator yang dijadikan pertimbangan dalam memperbaiki instrumen peniaian kemampuan berpikir tingkat tinggi. Setelah dilakukanrevisiterhadap saran yang diberikan validator, kemudian dilakukan analisis pada angket validasi. Hasil analisis validitas logis dapat

\begin{tabular}{|c|c|c|c|c|c|c|c|}
\hline \multirow{2}{*}{ No } & \multirow{2}{*}{ Komponen penilaian } & \multicolumn{3}{|c|}{ Validator } & \multirow{2}{*}{ Jumlah } & \multirow{2}{*}{$\begin{array}{c}\text { Nilai } \\
\text { Validitas }\end{array}$} & \multirow{2}{*}{ Kriteria } \\
\hline & & 1 & 2 & 3 & & & \\
\hline 1 & Materi & 29 & 28 & 33 & 90 & 3,34 & Valid \\
\hline 2 & Konstruksi & 29 & 29 & 31 & 89 & 3,33 & Valid \\
\hline 3 & Bahasa & 10 & 9 & 10 & 29 & 3,23 & Valid \\
\hline 4 & Berpikir tingkat tinggi & 16 & 15 & 16 & 47 & 3,12 & Valid \\
\hline \multicolumn{2}{|c|}{ Jumlah total nilai validitas } & & & & & 13,02 & \\
\hline \multicolumn{2}{|c|}{ Rata-rata nilai validitas } & & & & & 3,25 & Valid \\
\hline
\end{tabular}
dilihat pada Tabel 1 berikut.

Tabel 1. Hasil Validasi Instrumen Penilaian Kemampuan Berpikir Tingkat Tinggi

Berdasarkan Tabel 1 dapat diketahui rata-rata nilai validitas adalah sebesar 3,25 yang termasuk kategori valid. Hal ini menunjukkan bahwa instrumen penilaian kemampuan berpikir tingkat tinggi yang dikembangkan oleh penulis valid, baik dari segi materi, konstruksi, bahasa, dan berpikir tingkat tinggi, sehingga instrumen 
penilaian ini sudah dapat digunakan dalam penilaian terhadap peserta didik. Instrumen penilaian yang sudah valid, selanjutnya akan dilakukan uji praktikalitas oleh guru biologi SMAN 5 Padang.

Data validitas empiris diperoleh setelah soal diujikan kepada peserta didik. Data ini diperoleh dari hasil analisis butir soal lembar jawaban yang telah diisi peserta didik. Analisis butir soal secara kuantitatif dianalisis menggunakan program ANATES versi 4.09. Suatu instrumen penilaian dikatakan sudah memiliki validitas empiris yang tinggi jika telah memiliki indeks valid 0,50 sampai 0,75 (Arikunto, 2013: 89). Hasil analisis data dapat dilihat pada Tabel 2 berikut.

Tabel 2. Hasil Analisis Data Instrumen Penilaian Kemampuan Berpikir Tingkat Tinggi

\begin{tabular}{|c|c|c|}
\hline Jenis Soal & Validitas Empiris & Reliabilitas \\
\hline Pilihan ganda biasa & Valid sebanyak 21 soal & \multirow{3}{*}{$\begin{array}{c}\text { Reliabel } \\
\text { (kategori tinggi) }\end{array}$} \\
\hline Pilihan ganda sebab akibat & Valid sebanyak 5 soal & \\
\hline Pilihan ganda asosiasi & Valid sebanyak 6 soal & \\
\hline
\end{tabular}

Validitas logis didapatkan dari hasil analisis data validitas dari 3 orang validator, yang didasarkan pada aspek materi, konstruk, bahasa, dan kemampuan berpikir tingkat tinggi. Jika dilihat dari aspek materi didapatkan nilai rata-rata dari ketiga validator sebesar 3,34 dengan kategori valid. Aspek materi berkaitan mengenai keilmuan dan tingkat berpikir pada butir soal yang telah dirancang (Munadi, 2011). Hasil ini menunjukkan bahwa materi yang digunakan dalam instrumen penilaian ini, dapat digunakan untuk mengembangkan kemampuan berpikir tingkat tinggi peserta didik dan sesuai dengan Kompetensi Inti dan Kompetensi dasar. Kompetensi inti yang ketiga memiliki target lebih khusus yaitu kompetensi dasar yang dijabarkan menjadi indikator pencapaian kompetensi (Herlanti, 2015 307).

Aspek konstruksi instrumen penilaiankemampuan berpikir tingkat tinggi setelah dilakukan validitas logis didapatkan hasil 3,33 dengan kategori valid. Berdasarkan hasil ini dapat dikatakan bahwa pokok rumusan soal dirumuskan dengan jelas, tidak memberikan petunjuk kunci jawaban, dan bebas dari pernyataan negatif ganda. Soal kemampuan berpikir tingkat tinggi ini juga buat dengan pilihan jawaban yang homogen, dan pilihan jawaban yang berbentuk angka disusun bersadarkan urutan besar kecilnya angka atau kronologisnya. hal ini berhubungan dengan Sukardi (2012: 128), mengatakan bahwa semua pilihan jawaban sebaiknya direncanakan, memiliki panjang atau jumlah kata yang sama, dan tidak mengandung petunjuk jawaban benar.

Dilihat dari aspek bahasa, instrumen penilaian kemampuan berpikir tingkat tinggi yang dikembangkan termasuk dalam kategori valid dengan rata-rata 3,23 dari ketiga validator. Hal ini membuktikan bahwa instrumen penilaian ini sudah 
menggunakan bahasa yang sesuai dengan Ejaan Bahasa Indonesia (EBI), dan bahasa yang digunakan komunikatif, mudah dipahami, serta memakai kalimat yang jelas dan tidak ambigu. Kalimat yang sesuai kaidah bahasa Indonesia, struktur kalimat mudah dipahami dan tidak memberikan makna ganda (Harisman, 2014:2 12).

Dilihat dari aspek berpikir tingkat tinggi, instrumen ini sudah dikategorikan valid dengan nilai validitas sebesar 3,12. Widiawati, Joyoatmojo dan Sudianto (2018: 300) kemampuan berpikir tingkat tinggi mengedepankan peserta didik untuk menganalisis, mengevaluasi, dan mencipta. Instrumen yang dikembangkan sudah berada dalam tingkatan kognitif menganalisis (C4), mengevaluasi (C5), dan mencipta (C6).

Soal dengan tingkat kognitif menganalisis merupakan soal yang menuntut peserta didik untuk memecah materi menjadi bagian-bagian penyusunnya dan mendeteksi bagaimana hubungan antar bagian tersebut, dan hubungannya dengan keseluruhan struktur dan tujuan. Soal dengan tingkat kognitif menganalisis (C4) dihasilkan sebanyak 24 soal. Soal C4 ini menggunakan stimulus berupa gambar, narasi, grafik, dan tabel. Soal pada level mengevalusi merupakan soal yang menuntut peserta didik untuk mengambil sebuah keputusan berdasarkan kriteria-kriteria tertentu.

Soal dengan tingkat mengevaluasi (C5) dihasilkan sebanyak 3 soal. Soal yang berada pada level mencipta merupakan soal yang menuntut peserta didik untuk memadukan berbagai hal untuk terbentuknya sesuatu yang baru, koheren atau membuat suatu produk yang belum ada sebelumnya. Soal pada tingkat C6 ini dihasilkan sebanyak 5 soal. Instrumen penilaian ini juga telah menggunakan stimulus yang menarik yaitu berupa tabel, gambar, grafik, wacana dan narasi yang berfungsi baik sesuai dengan konteks materi. Instrumen ini sudah dapat digunakan untuk melatih peserta didik mengembangkan kemampuan berpikir tingkat tinggi.

Dilihat dari keempat aspek didapatkan rata-rata validitassebesar 3,25 dari tiga orang validator. Berdasarkan hasil tersebut dapat dikatakan bahwa instrumen penilaian sudah memenuhi validitas logis dan dapat digunakan sebagai instrumen penilaian untuk peserta didik pada materi ruang lingkup biologi. Namun sebelum digunakan harus dilakukan uji praktikalitas dan validitas empirisnya, agar instrumen yang digunakan benar-benar valid, serta dapat melatih peserta didik dalam mengembangkan kemampuan berpikir tingkat tingginya.

Validitas empiris didapatkan dari hasil analisis butir soal dengan menggunakan ANATES versi 4.0.9. Soal yang dianalisis sebanyak 40 butir soal pada 30 orang peserta didik kelas X MIPA 5 SMAN 5 Padang. Instrumen penilaian dikatakan valid, jika memiliki validitas empiris yang sesuai dengan pengalaman. Berdasarkan analisis butir soal yang dilakukan, dapat dikatakan bahwa instrumen penilaian kemampuan berpikir tingkat tinggi ini sudah valid berdasarkan validitas empirisnya. Dari analisis ini dihasilkan 32 soal yang valid, dan 8 soal yang tidak 
valid. Soal yang tidak valid tidak dapat digunakan. Arikunto (2012: 89) mengatakan bahwa jika nilai $r$ terletak diantara 0,00 sampai 0,20 maka koefisien korelasi ini diinterprestasikan memiliki korelasi sangat rendah, sehingga tidak menunjukkan signifikan atau tidak valid.

Instrumen penilaian kemampuan berpikir tingkat tinggi ini sudah reliabel dengan nilai sebesar 0,72. Sebagaimana yang dikatakan Supardi (2015: 114) bahwa suatu tes dikatakan reliabel (memiliki reliabilitas yang tinggi) bila $\mathbf{r}_{11}$ sama dengan atau lebih besar dari pada 0,70. Instrumen yang reliabel yaitu istrumen yang memberikan hasil yang sama, jika diteskan pada kelompok yang sama pada waktu yang berbeda. Hal ini sesuai dengan pendapat Sukardi (2012: 43), yang mengatakan bahwa suatu tesdikatakan memiliki reliablitas yang tinggi, apabila tes yang dibuat mempunyai hasil yang konsisten dalam mengukur yang hendak diukur.

\section{PENUTUP}

Berdasarkan hasil dan pembahasan yang dilakukan maka dapat disimpulkan bahwa instrumen penilaian Kemampuan Berpikir Tingkat Tinggi Pada Materi Ruang Lingkup Biologi SMA valid dan reliabel. Hal ini berarti instrumen penilaian ini merupakan alat ukur yang tepat dan dapat dipercaya untuk mengukur kemampuan berpikir tinggi siswa pada materi ruang lingkup biologi. Hasil penelitian ini dapat digunakan sebagai masukan kepada guru dan calon guru agar memperhatikan validitas dan reliabilitas instrumen penilaian yang digunakan.

\section{REFERENSI}

Arikunto, S. 2012. Dasar-dasarEvaluasi Pendidikan. Jakarta: BumiAksara.

Arikunto, S. 2013. Dasar-dasarEvaluasi Pendidikan. Jakarta: BumiAksara.

Harisman, Y. 2014. Validitas dan Praktikalitas Modul untuk Materi Fungsi Pembangkit pada Perkuliahan Matematika Diskrit di STKIP PGRI Sumatra Barat. Admathedu, Vol. 4, No.2: 207-214.

Herlanti, Y. 2015. Analisis Domain Pengetahuan dan Kognitif pada Kurikulum Indonesia Tahun 1984-2013 Mata Pelajaran BiologiSekolahMenengahAtas, Seminar Nasional XII. Solo: Pendidikan Biologi FKIPUNS.

Sukardi. 2012. Evaluasi Pendidikan Prinsip dan Operasionalnya. Jakarta: Bumi Aksara.

Syafredi, K. 2018. Hasil Penelitian "Efek Model Pembelajaran Discovery dan KreativitasTerhadapKemampuanBerpikir Tingkat Tinggi Fisika Siswa”. Sukabumi: Jejak. 
Trianto. 2012. Model PembelajaranTerpadu. Jakarta: BumiAksara.

Mukhlisah, AM. 2015. Pengembangan Kognitif Jean Piaget dan Peningkatan Belajar Anak DISKALKULIA (Studi Kasus Pada MI Pangeran Diponegoro Surabaya. Jurnal Kependidikan Islam, Vol. 6, No. 2: 118-131.

Munadi, S. 2011. Analisis Validasi Kualitas Soal Tes Hasil Belajar pada Pelaksanaan Program Pembelajaran. Cakrawala Pendidikan, Th. XXX, No. 1: 145-159.

Prasetiyo, N.A. dan Pertiwi, P. 2017. Pengembangan Buku Ajar Berbasis Lingkungan Hidup Pada Mata Kuliah Biologi di Universitas Tribhuwana Tungga Dewi, Jurnal Pendidikan Biologi Indonesia, Vol.3, No.1:19-27.

Riyani, R., Syafdi, M., dan Hanifah. 2017. Uji Validitas Pengembangan Tes untuk Mengukur Kemampuan Pemahaman Relasional pada Materi Persamaan Kuadrat Siswa Kelas VIII SMP. Jurnal Penelitian Pembelajaran Matematika Sekolah, Vol.1, No.1: 60-65.

Rofiah, E., Aminah, N.S., Ekawati, E.Y. 2013. Penyusunan Instrumen Tes Kemampuan Berpikir Tingkat Tinggi Fisika pada Siswa SMP. Jurnal Pendidikan Fisika,1 (2): 1722.

Widiawati, L. dan Joyoatmojo, S, dan Sudiyanto. 2018. Highr Order Thinking Skills pada Pembelajaran Abad 21 (Pre Research). Journal Proceeding, Vol.4, No.1: 295-301.

Yusuf, M. 2017. Asesmen dan Evaluasi Pendidikan: Pilar PenyediaInformasi dan KegiatanPengendalianMutu Pendidikan. Jakarta: Prenada Media Group. 